\title{
Filariosis por Setaria equina en un caballo del estado de Yucatán, México.
}

\section{Caso Clínico}

Roger I. Rodríguez-Vivas ${ }^{1}$, Ubaldo Dzul-Canché1, Eduardo M. Sierra-Lira², Francisco J. Aranda-Cirerol ${ }^{2}$.

${ }^{1}$ Departamento de Parasitología, ${ }^{2}$ Departamento de Medicina Interna y Cirugía, Facultad de Medicina Veterinaria y Zootecnia, Universidad Autónoma de Yucatán. Mérida, Yucatán, México.

\section{RESUMEN.}

Introducción. Setaria equina es un nematodo que viven en la cavidad peritoneal de los equinos. En su ciclo biológico actúa como huésped intermediario los mosquitos de los géneros Anopheles, Aedes y Culex.

Caso clínico. Se presentó un caso de un caballo macho de la raza criolla de tres años de edad, procedente del municipio de Río Lagartos, Yucatán, México. El caballo fue sometido a una castración y en el líquido testicular se encontró la presencia de 3 hembras que midieron de largo 83 mm (7593) y 4 machos de $54.5 \mathrm{~mm}$ (43-64) de largo. Los nematodos fueron clasificados como Setaria equina.

Discusión. S. equina puede tener localizaciones erráticas, sobre todo en la cavidad pleural, ojos, cerebro, médula espinal y los testículos de los equinos, sin presentar signos clínicos. No obstante, la larva en el globo ocular y en el sistema nervioso central, puede causar serios daños. A pesar de que S. equina tiene distribución mundial, en el sureste mexicano no ha sido reportado como parásito en los equinos. (Rev Biomed 2000; 11:183-185)

Palabras clave: Setaria equina, equino, Yucatán, México.

\section{SUMMARY.}

Filariosis for Setaria equina in a horse from the state of Yucatan, Mexico.

Introduction. Setaria equina is a nematode which lives in the peritoneal cavity of horses. Mosquitos from the genus Anopheles, Aedes and Culex are involved as intermediate hosts in the parasite's life cycle.

Clinical case. The case of a 3 year old criollo breed male horse from the county of Rio Lagartos, Yucatan, Mexico, is reported. During castration of the horse, 3 female parasite of $83 \mathrm{~mm}$ (75-93) length and 4 males of $54.5 \mathrm{~mm}$ (43-64) length were found in the testicle liquid. The nematodes were classified as Setaria equina.

Solicitud de sobretiros: Roger I. Rodríguez-Vivas. Departamento de Parasitología, Facultad de Medicina Veterinaria y Zootecnia, Universidad Autónoma de Yucatán. Apdo. Postal 4-116 Itzimná. Mérida, Yucatán, México. Fax: (9) 9423205. E-mail: rvivas@tunku.uady.mx 


\section{RI Rodríguez-Vivas, U Dzul-Canché, EM Sierra-Lira, FJ Aranda-Cirerol.}

Discussion. S. equina can have erratic locations, mainly in the pleural cavity, the eye, the brain, the spinal medulla and in the testicles of horses, without showing any clinical signs. However, the larvae in the ocular globe and the central nervous system can cause serious damage. Although S. equina is found worldwide, the presence of this parasite in horses has not been reported in Southern Mexico. (Rev Biomed 2000; 11:183-185)

Key words: Setaria equina, equine, Yucatán, México.

\section{INTRODUCCION.}

La filariosis constituye un grupo de procesos producidos por filáridos, cuyos adultos viven en el tejido conjuntivo subcutáneo, cavidad pleural, pulmones, espacios aracnoideo, intestinos, tendones y cavidades corporales de los equinos. Tienen un ciclo biológico indirecto, utilizando como huéspedes intermediarios especies de artrópodos hematófagos (1). En consecuencia la filariosis es más frecuente en meses calurosos en donde abundan los dípteros transmisores $(2,3)$.

Una de las filariosis más frecuentes en los equinos es la setariosis causada por Setaria equina cuyos adultos pueden tener localizaciones erráticas, sobre todo en la cavidad pleural, ojos y testículos $(2,4)$. En su ciclo biológico actúan como huéspedes intermediarios mosquitos de los géneros Anopheles, Aedes y Culex $(3,5,6)$. Las microfilarias llegan a la circulación y son ingeridas por los vectores, en los que se transforman en larva 3 de 10 a 15 días. Después de la picadura de un mosquito parasitado, el verme llega a la madurez sexual en un período de 8 a 10 meses (3).

\section{CASO CLINICO.}

Se reporta el caso de un caballo macho de la raza criolla de tres años de edad, procedente del municipio de Río Lagartos, Yucatán, México. El clima de este municipio es tropical sub-húmedo con lluvias en verano. La temperatura media anual fluctúa entre $\operatorname{los} 24^{\circ} \mathrm{C}$ y $27^{\circ} \mathrm{C}$, humedad relativa media de $82 \%$ y precipitación pluvial anual de 1000 a $1100 \mathrm{~mm}$. El animal fue alimentado exclusivamente en praderas establecidas con zacate Guinea (Panicum maximum) y teniendo acceso a agua ad libitum.

En el examen físico externo, los testículos se encontraron aparentemente normales. El caballo fue sometido a un procedimiento quirúrgico de castración con fines reproductivos. Durante la castración se incidió con un bisturí la línea media de la base de los testículos, separando la piel y la túnica albugínea para exponer los testículos y el líquido testicular. En este último se encontró la emanación de siete nemátodos de color blanco en forma de espiral. Los nemátodos fueron depositados en solución salina fisiológica y enviados al laboratorio de Parasitología de la Facultad de Medicina Veterinaria y Zootecnia de la Universidad Autónoma de Yucatán para su identificación. Se encontraron 3 hembras que midieron de largo $83 \mathrm{~mm}$ (75-93) y 4 machos de $54.5 \mathrm{~mm}$ (43-64) de largo. Los nemátodos presentaron en el extremo anterior prominencias peribucales laterales grandes y otras pequeñas simples, en las regiones dorsal y ventral. Los machos en su extremo posterior presentaron espícula izquierda de $0.64 \mathrm{~mm}$ de largo (63-65 $\mathrm{mm})$ y derecha de $0.20 \mathrm{~mm}(0.15-0.25 \mathrm{~mm}) \mathrm{de}$ largo. La cola de las hembras terminaban de forma simple. Los parásitos fueron clasificados como Setaria equina, Alildgaar, 1789 (6).

\section{DISCUSION.}

El parásito adulto del género Setaria en su localización en las cavidades peritoneal, pleural, y en los testículos no produce signos clínicos, pero la infección del globo ocular produce iritis, queratitis y conjuntivitis, pudiéndose llegar a la ceguera $(3,4)$. Además, la presencia de larvas de S. equina en el sistema nervioso central puede causar serios daños neurológicos (2).

\section{Revista Biomédica}


S. equina tiene una distribución mundial, presentándose generalmente en zonas tropicales o subtropicales (3). La tasa de infección en los equinos puede ser alta, y en áreas endémicas, pueden estar infectados hasta el 50\% de los caballos (6). A pesar de esta situación, en el sureste mexicano no ha sido reportado como parasitosis en los equinos. Es necesarios hacer una investigación exhaustiva para conocer su distribución y la importancia de esta parasitosis en la población equina de la región.

\section{REFERENCIAS.}

1. Maloufi F. Equine parafilariosis in Iran. Vet Parasitol 1995; 56:189-97.

2. Bowman DD. Goergis' Parasitology for Veterinarians. Sixth edition. Philadelphia: WB Saunders Company; 1995. p.220-1.

3. Meana A y Rojo VFA. Parasitosis cutánea. En: Parasitología Veterinaria, Campillo MC y Rojo VFA ed. Madrid, España: McGraw-Hill Interamericana; 1999. p.602-29.

4. Jemelka ED. Removal of Setaria digitata from the anterior chamber of the equine eye. MV/SAC, May, 1976:673-5.

5. Quiroz RH. Parasitología y Enfermedades Parasitarias de Animales Domésticos. México: Limusa; 1988. p.63740.

6. Soulsby EJE. Parasitología y Enfermedades Parasitarias en los Animales Domésticos. México: Interamericana; 1988. p.317. 